\title{
Air Annealing Effect on Oxygen Vacancy Defects in Al-doped ZnO Films Grown by High-Speed Atmospheric Atomic Layer Deposition
}

\author{
Chia-Hsun Hsu ${ }^{1}$, Xin-Peng Geng ${ }^{1}$, Wan-Yu Wu ${ }^{2}$, Ming-Jie Zhao ${ }^{1}$, Xiao-Ying Zhang ${ }^{1}$, \\ Pao-Hsun Huang ${ }^{3}$ iD and Shui-Yang Lien ${ }^{1,2,4, *}$ \\ 1 School of Opto-electronic and Communication Engineering, Xiamen University of Technology, \\ Xiamen 361024, China; chhsu@xmut.edu.cn (C.-H.H.); gexipe@163.com (X.-P.G.); \\ 2015000077@xmut.edu.cn (M.-J.Z.); xyzhang@xmut.edu.cn (X.-Y.Z.) \\ 2 Department of Materials Science and Engineering, Da-Yeh University, ChungHua 51591, Taiwan; \\ wywu@mail.dyu.edu.tw \\ 3 School of Information Engineering, Jimei University, Xiamen 361021, China; ph.huang@jmu.edu.cn \\ 4 Fujian Key Laboratory of Optoelectronic Technology and Devices, Xiamen University of Technology, \\ Xiamen 361024, China \\ * Correspondence: sylien@xmut.edu.cn; Tel.: +86-5926291615; Fax: +86-5926291615
}

Academic Editors: Braulio García-Cámara and Ricardo Vergaz

Received: 5 October 2020; Accepted: 28 October 2020; Published: 30 October 2020

\begin{abstract}
In this study, aluminum-doped zinc oxide ( $\mathrm{Al}: \mathrm{ZnO})$ thin films were grown by high-speed atmospheric atomic layer deposition (AALD), and the effects of air annealing on film properties are investigated. The experimental results show that the thermal annealing can significantly reduce the amount of oxygen vacancies defects as evidenced by X-ray photoelectron spectroscopy spectra due to the in-diffusion of oxygen from air to the films. As shown by $X$-ray diffraction, the annealing repairs the crystalline structure and releases the stress. The absorption coefficient of the films increases with the annealing temperature due to the increased density. The annealing temperature reaching $600{ }^{\circ} \mathrm{C}$ leads to relatively significant changes in grain size and band gap. From the results of band gap and Hall-effect measurements, the annealing temperature lower than $600{ }^{\circ} \mathrm{C}$ reduces the oxygen vacancies defects acting as shallow donors, while it is suspected that the annealing temperature higher than $600^{\circ} \mathrm{C}$ can further remove the oxygen defects introduced mid-gap states.
\end{abstract}

Keywords: atomic layer deposition; aluminum-doped zinc oxide; annealing; oxygen vacancy

\section{Introduction}

Metal oxides are widely used in many applications such as optical coatings, transparent conducting oxides (TCOs), photocatalysis, sensors and photo-electrochemistry [1-7]. TCOs have attracted lots of attention because they show simultaneously conductivity and optical transparency. In the past fifty years, indium tin oxide (ITO) has become the most widely used TCO for optoelectronic devices due to its high transmittance of $\sim 90 \%$ in the visible range and low resistivity $\left(\sim 2 \times 10^{-4} \Omega\right.$-cm) with mobility of about $40 \mathrm{~cm}^{2} / \mathrm{Vs}$ and high carrier concentration of $10^{21} \mathrm{~cm}^{-3}[8,9]$. However, ITO faces several challenges. The scarcity of indium element may result in severely increased material cost. The commonly used sputtering process for preparing ITO can cause damage to the underlying layer as appears in the increased parasitic absorption at the TCO/Si interface of the heterojunction silicon solar cells [10-12]. The high carrier concentration of ITO reduces short-circuit current of solar cells if it is used as a window layer. The development of alternative materials with low cost and high mobility is necessary. Among all materials, aluminum-doped zinc oxide $(\mathrm{Al}: \mathrm{ZnO})$ is the most widely researched n-type TCOs owing to its excellent properties similar to ITO and comparability to various deposition 
techniques, such as sputter [13], spray pyrosis [14], plasma enhanced chemical vapor deposition [15], and pulsed laser deposition [16]. However, the $\mathrm{Al}: \mathrm{ZnO}$ is generally used as an interconnection layer in optoelectronics, such as tandem thin film solar cells and polymer solar cells, but not used as an electrode since the ITO still outperform $\mathrm{Al}: \mathrm{ZnO}$ in this aspect. Recently, atomic layer deposition (ALD) has become a very attractive approach to prepare TCOs $[17,18]$. The ALD technique is known for its unique features such as the deposition of conformal layer over a variety of substrate types and geometries, pinhole-free films with a very low defect concentration compared to other techniques, and the controllability of film thickness at sub-nanometer level. In some studies, ALD Al:ZnO has reached a low resistivity comparable to ITO [19]. It has been reported a better conversion efficiency of polymer solar cells with ALD Al:ZnO electrodes compared to that using ITO-coated glass [20]. Effects of the ALD deposition parameters such as substrate temperature, purge time, precursor dosing time on the properties of the $\mathrm{Al}: \mathrm{ZnO}$ films are systematically studied [21-24]. However, the post-annealing effects on the ALD Al:ZnO are rarely reported. In the literature the post-annealing effects are mostly for magnetron sputtered $\mathrm{Al}: \mathrm{ZnO}$. For instance, Kim et al. reported an increased carrier concentration of the Al:ZnO films prepared by sputtering after vacuum annealing [25].Lin et al. reported a decreased carrier concentration in the case of nitrogen or oxygen annealing [26], while Zhou et al. observed a decreased resistivity of the $\mathrm{Al}: \mathrm{ZnO}$ after annealing in nitrogen and oxygen mixture [27]. The results of the annealed $\mathrm{Al}: \mathrm{ZnO}$ are controversial, and the related mechanism is not fully understand.

In this study, the $\mathrm{Al}: \mathrm{ZnO}$ thin films were prepared using high-growth rate atmospheric ALD (AALD). The processing time of one ALD cycle is about $3 \mathrm{~s}$, which is nearly 20 times shorter than vacuum-type ALD ( $1 \mathrm{~min}$ for one ALD cycle). Furthermore, the growth rate per cycle of the AALD $\mathrm{Al}: \mathrm{ZnO}$ films is $0.94 \AA / \mathrm{cycle}$, corresponding to about $0.3 \AA / \mathrm{s}$. This value is lower than that $(0.5-3 \AA / \mathrm{s})$ obtained by using sputter [28-31], but in terms of total deposition time, the AALD method would take more advantages since it does not require a vacuum environment. For example, for a $60 \mathrm{~nm}$-thick $\mathrm{Al}: \mathrm{ZnO}$ film, the AALD method takes about $40 \mathrm{~min}$ to finish the deposition, whereas the sputter technique may require more time as it needs to reach high degree of vacuum before deposition. The AALD process thus demonstrates high potential for the industrial applications. Instead of using traditional multilayered $\mathrm{Al}_{2} \mathrm{O}_{3} / \mathrm{ZnO}$ structure, the $\mathrm{Al}$ and $\mathrm{Zn}$ metal precursors are co-injected into the deposition zones. The films are annealed at $300-800{ }^{\circ} \mathrm{C}$ to manipulate the oxygen vacancies. The effects of the air annealing temperature on the optical, electrical and structural properties are investigated.

\section{Results and Discussion}

The chemical states of $\mathrm{O}$ for the AALD Al:ZnO thin films with different annealing temperatures are investigated by X-ray photoelectron spectroscopy (XPS), as shown in Figure 1a. The peaks at around 530, 1020, and $1050 \mathrm{eV}$ are assigned to the $\mathrm{O} 1 \mathrm{~s}, \mathrm{Zn} 2 \mathrm{p}_{3 / 2}$, and $\mathrm{Zn} 2 \mathrm{p}_{1 / 2}$ core levels, respectively. No carbon peaks $(\sim 284.5 \mathrm{eV})$ are observable, indicating no or very low carbon content as the surface of the samples was sputtered before the XPS measurement to remove the surface contamination. In addition, the lack of carbon peaks suggests the nearly full ALD reactions of the diethylzinc (DEZ) and trimethylaluminum (TMA) precursors, otherwise the methyl groups in the precursors will remain in the deposited films. The Al peak at $75.6 \mathrm{eV}$ is hardly observed due to the low content of $<0.7$ at. $\%$ as shown in Figure $1 \mathrm{~b}$. In order to investigate the chemical states, the $\mathrm{O} 1 \mathrm{~s}$ spectra of the samples with different annealing temperature (Figure $1 \mathrm{c}-\mathrm{h}$ ) are deconvoluted into two peaks, which are centered at 530.6 and $532.1 \mathrm{eV}$. In the literature, a peak at the lower binding energies of $530-531 \mathrm{eV}$ is generally attributed to the $\mathrm{O}^{2-}$ binding at lattice points of $\mathrm{ZnO}$, while the peak at the higher binding energies (531-532 eV) is ascribed to oxygen vacancies [32-38]. We thus assign the peaks at 530.6 and $532.1 \mathrm{eV}$ as the lattice oxygen $\left(\mathrm{O}_{\mathrm{L}}\right)$ and oxygen vacancies defects $\left(\mathrm{O}_{\mathrm{D}}\right)$, respectively. Increasing annealing temperature from 300 to $500{ }^{\circ} \mathrm{C}$ leads to high $\mathrm{O}_{\mathrm{D}} /\left(\mathrm{O}_{\mathrm{L}}+\mathrm{O}_{\mathrm{D}}\right)$ ratios of around $30.8 \%-35.4 \%$. The ratio reduces to $27.4 \%$, suggesting that the oxygen vacancies are filled by the oxygen from the annealing environment. As the oxygen vacancies affect optoelectronic properties of the $\mathrm{Al}: \mathrm{ZnO}$ films [39], the significant variation 
of the $\mathrm{O}_{\mathrm{D}} /\left(\mathrm{O}_{L}+\mathrm{O}_{\mathrm{D}}\right)$ ratio from $35.4 \%$ to $14.5 \%$ indicates the high tunability of the film properties depending on the annealing temperature.

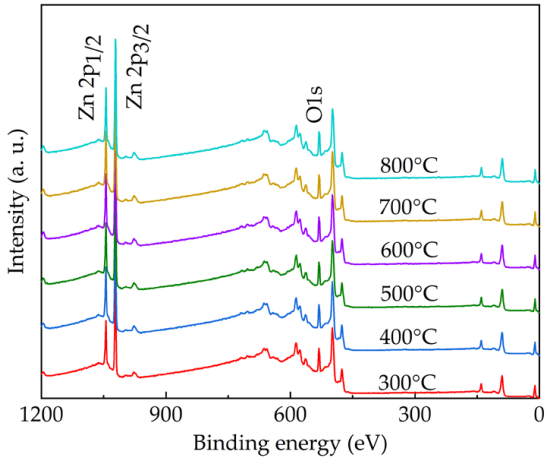

(a)

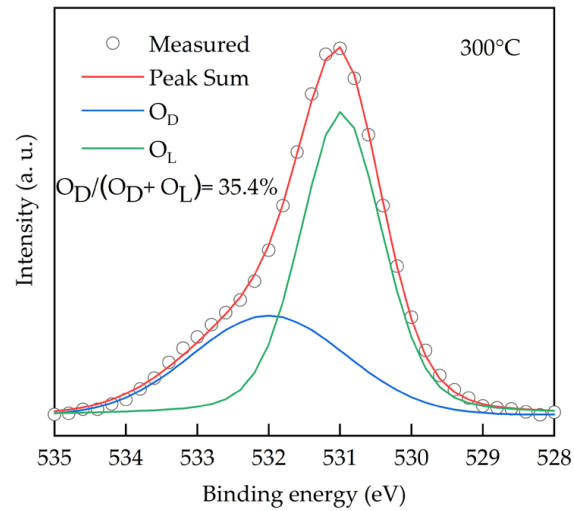

(c)

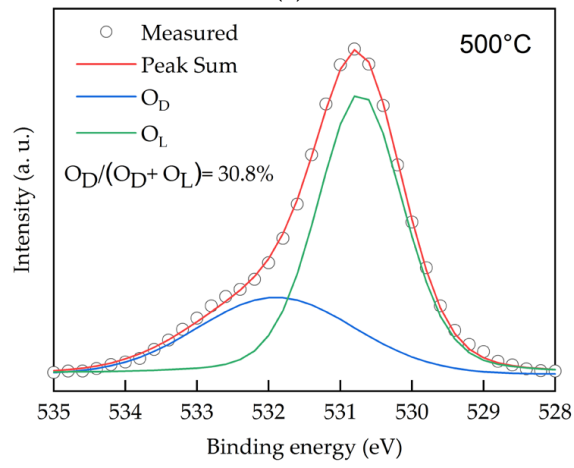

(e)

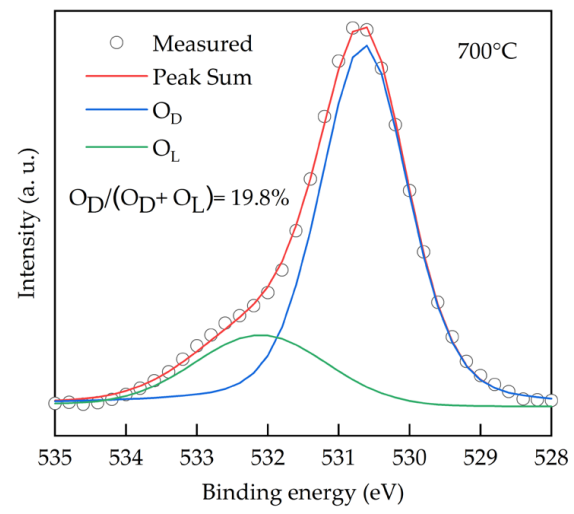

(g)

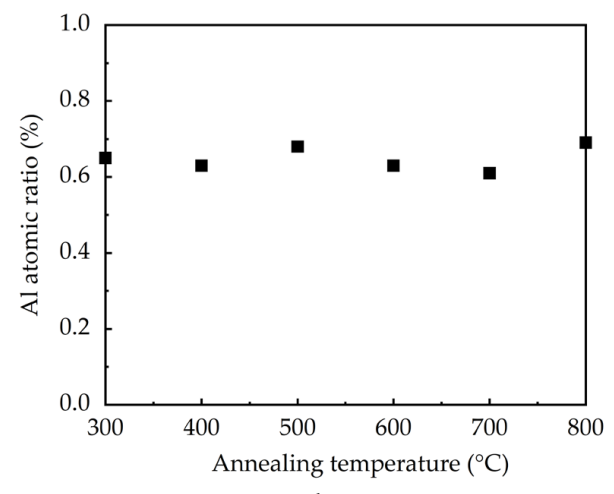

(b)

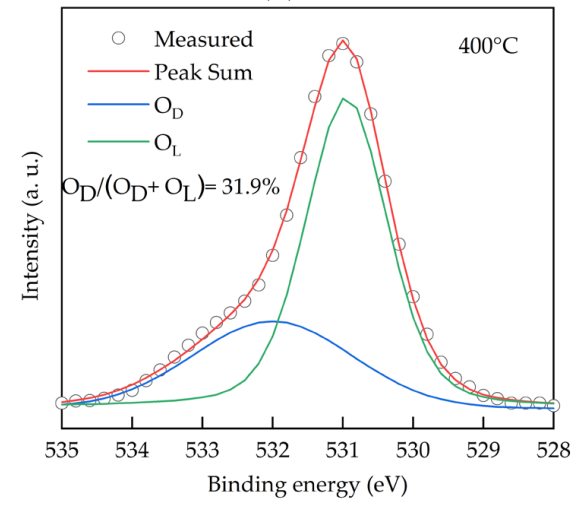

(d)

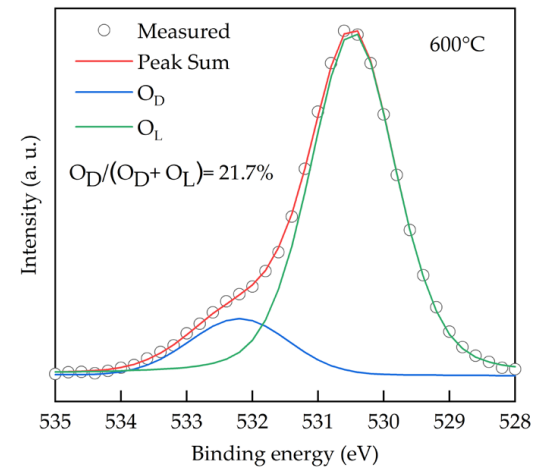

(f)

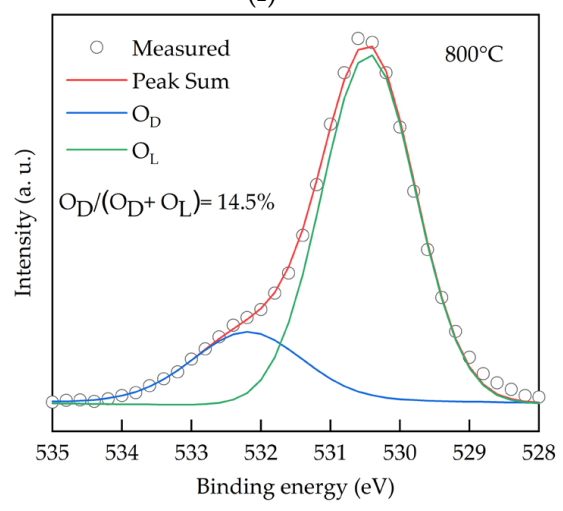

(h)

Figure 1. (a) XPS spectra, (b) Al content and (c-h) O 1s spectra for the AALD Al:ZnO thin films annealed at different temperature. 
Figure 2a shows the X-ray diffraction (XRD) patterns for the atmospheric $\mathrm{Al}: \mathrm{ZnO}$ films with different annealing temperature. All the films have the peaks at $31.83^{\circ}, 36.36^{\circ}, 56.69^{\circ}$, and $68.14^{\circ}$ designated to (100), (101), (110), and (112) lattice planes of polycrystalline hexagonal wurtzite structure $\mathrm{ZnO}$, respectively (JCPDS \#36-1451) [40]. The preferred orientation is (100). All the samples do not show any peaks related to Al-related oxides, and this suggests that $\mathrm{Al}$ ions are well-incorporated into the wurtzite structure in the investigated annealing temperature range. The narrowing of the dominant (100) peaks with the increase of the annealing temperature indicates the improved crystallinity. Figure $2 b$ illustrates the full-width-half-maximum (FWHM) of the (100) peaks and the corresponded crystallite size calculated using Scherrer's equation as given by [41]:

$$
D=\frac{\mathrm{k} \lambda}{\beta \cos \theta},
$$

where $D$ is the average crystallite size, $\mathrm{k}$ is the Scherrer constant $(0.9), \lambda$ is the wavelength of the $\mathrm{X}$-ray radiation $(0.15418 \mathrm{~nm}), \beta$ is FWHM, and $\theta$ is the Bragg's diffraction angle of the (100) peak. At the annealing temperatures of $300-500{ }^{\circ} \mathrm{C}$, the crystallite size is around $20.5 \mathrm{~nm}$. Further increasing the annealing temperature from 500 to $800{ }^{\circ} \mathrm{C}$ leads to an enlargement of the crystallite size from 20.5 to $26.9 \mathrm{~nm}$ due to recrystallization of the films. In addition to the repair of the crystalline structure, the annealing treatment renders oxygen atoms/molecules able to diffuse from the air into the $\mathrm{Al}: \mathrm{ZnO}$ films to fill the oxygen vacancies. The increased annealing temperature enhances this process, thereby improving the crystal growth and crystallite size. As oxygen vacancies are known to induce stress to the lattice structure [42], the reduction of the oxygen vacancies defects through high-temperature annealing releases the stress. This is also reflected on the decreased trend of the microstrain $(\varepsilon)$, shown in Figure 2c, as calculated by [43]:

$$
E=(0.9 / D-1 / D)^{*} \lambda / \sin \theta^{\prime}
$$

Further, the restoration of the lattice structure should increase the interplanar distance between crystal faces. The interplanar distance (d-spacing) of the (100) preferred orientation for the samples is calculated by the following equation [44]:

$$
2 \mathrm{~d} \sin \theta=\mathrm{n} \lambda,
$$

where $\mathrm{n}$ is the diffraction order. The 2-theta value shifts from $32^{\circ}$ to $31.9^{\circ}$ when the annealing temperature increases from 300 to $800^{\circ} \mathrm{C}$. Accordingly, the d-spacing increases from 2.79 to $2.801 \AA$ as shown in Figure 2d.

Figure $3 \mathrm{a}-\mathrm{f}$ show the scanning electron microscopy (SEM) topological images for the AALD $\mathrm{Al}: \mathrm{ZnO}$ films with different annealing temperature. At $300^{\circ} \mathrm{C}$, the sample has elongated grains parallel to the substrate, which is in accordance with the XRD result showing a (100) preferred orientation. The grain size changes with varying the annealing temperature. By drawing a diagonal line, we can estimate the average grain size of the samples. The increasing trend of the average grain size with the annealing temperature agrees with the XRD result. In particular, the grain size well-matches the crystallite size determined from XRD at the annealing temperatures lower or equal to $600{ }^{\circ} \mathrm{C}$, whereas at the annealing temperature of $800^{\circ} \mathrm{C}$ the grain sizes are apparently larger than expected, suggesting that the high-temperature annealing causes the crystallites to aggregate rather than merge into larger crystals. The aggregation may lead to discontinuity/voids as clearly observed in Figure 3f. The presence of the voids can cause shunting or increased leakage current when the $\mathrm{Al}: \mathrm{ZnO}$ films are used as the TCO of optoelectronic devices. Furthermore, in some applications the ALD films are mostly prepared at a thin thickness (few to tens nanometers), and the adverse influence of these voids could be more magnified. A proper annealing temperature is thus important for the AALD Al:ZnO films. 


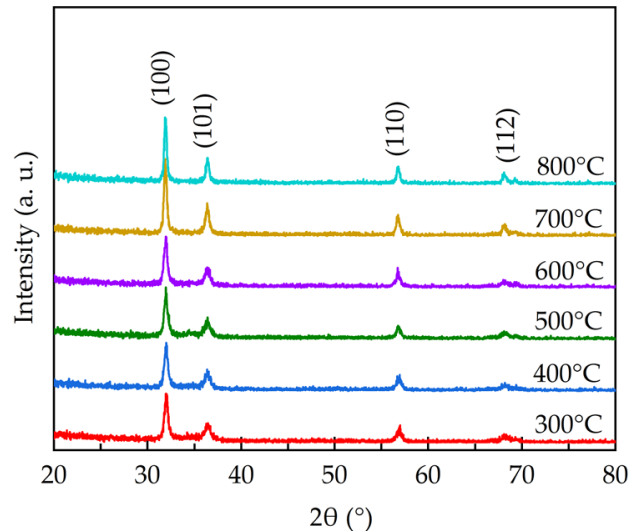

(a)

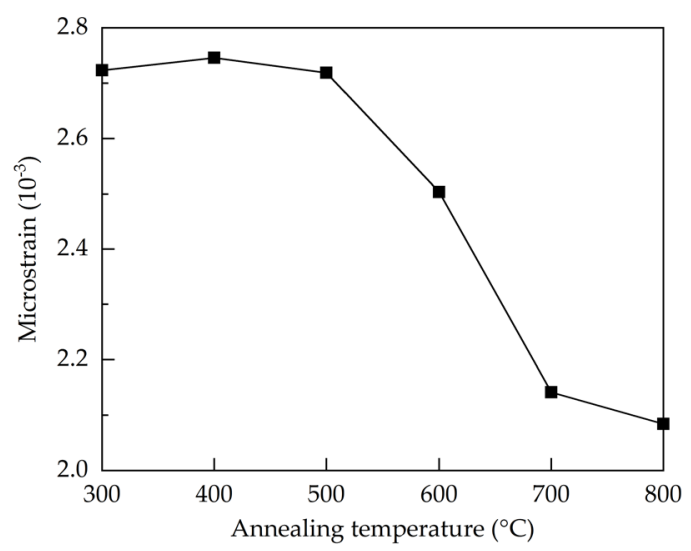

(c)

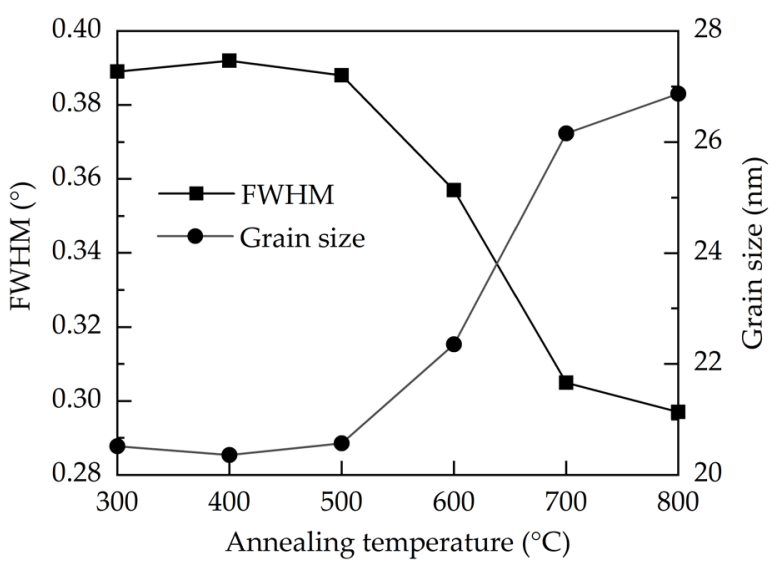

(b)

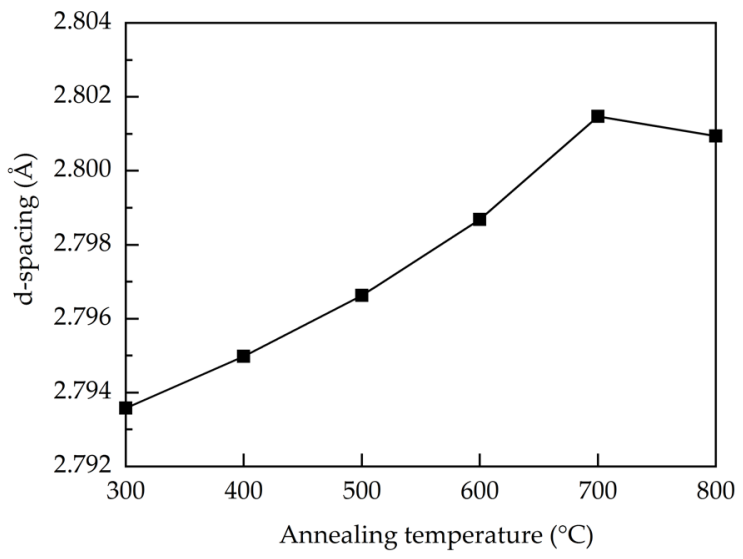

(d)

Figure 2. (a) XRD patterns, (b) FWHM and grain size, (c) microstrain, and (d) d-spacing of the AALD $\mathrm{Al}: \mathrm{ZnO}$ thin films annealed at different temperature.

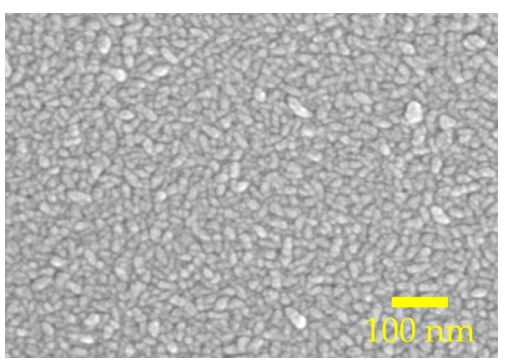

(a)

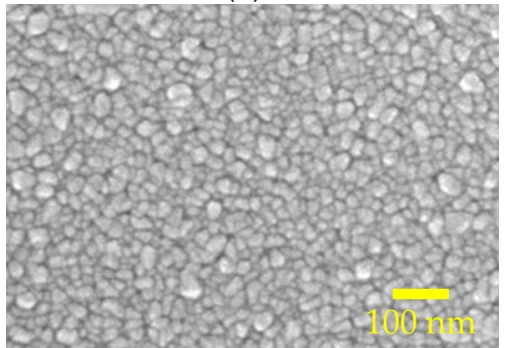

(d)

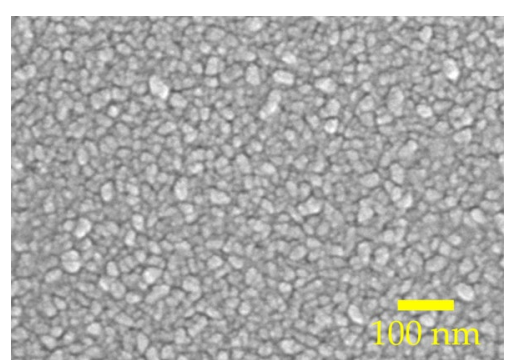

(b)

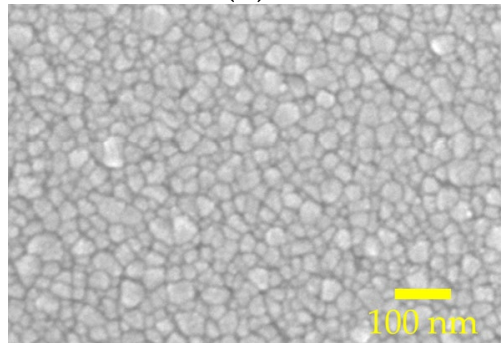

(e)

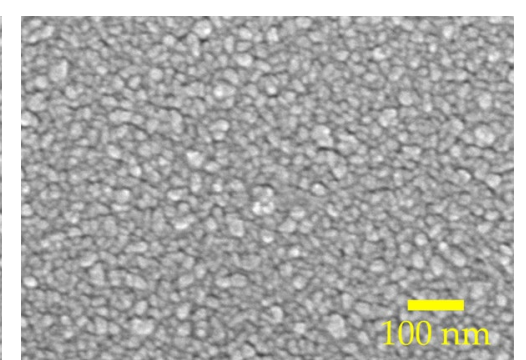

(c)

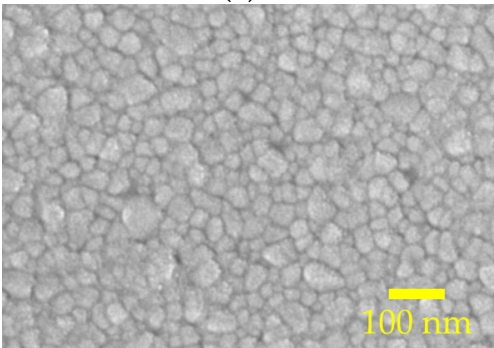

(f)

Figure 3. SEM morphological images of the AALD Al:ZnO films annealed at (a) 300, (b) 400, (c) 500, (d) $600,(\mathbf{e}) 700$, and (f) $800{ }^{\circ} \mathrm{C}$. 
The resistivity, mobility, and carrier concentration $\left(\mathrm{N}_{\mathrm{e}}\right)$ determined by Hall-effect measurements are shown in Figure 4. The resistivity remains $1.12 \times 10^{-3} \Omega-\mathrm{cm}$ at the annealing temperatures of $300-500{ }^{\circ} \mathrm{C}$, and then it decreases to a minimum of $9 \times 10^{-4} \Omega$-cm at $600{ }^{\circ} \mathrm{C}$, as shown in Figure $4 \mathrm{a}$. Further increasing the annealing temperature to $800{ }^{\circ} \mathrm{C}$ leads to a significant increase in resistivity to $2.7 \times 10^{-3} \Omega$-cm. It is known that the resistivity should be inversely proportional to the product of the mobility and carrier concentration. As shown in Figure $4 \mathrm{~b}$, the increased annealing temperature improves the mobility due to the enhanced crystalline structure and grain size. Noted that at $800{ }^{\circ} \mathrm{C}$ the relatively small increment of the mobility is possibly related to the adverse effect of the crystallite aggregation as discussed in the SEM results. In contrast, the carrier concentration reduces with increasing the annealing temperature as a consequence of the removal of the oxygen vacancies. Therefore, the net result of the competing effect of the increased mobility and reduced carrier concentration at increasing annealing temperature shows that the $600{ }^{\circ} \mathrm{C}$-annealed sample has the lowest resistivity.

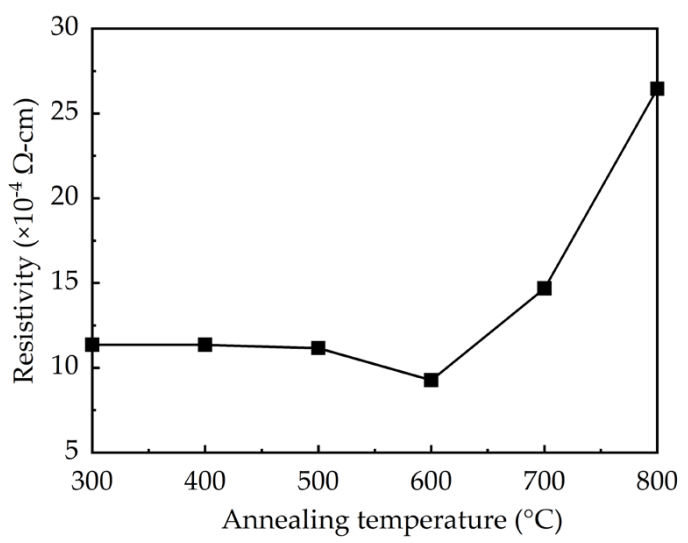

(a)

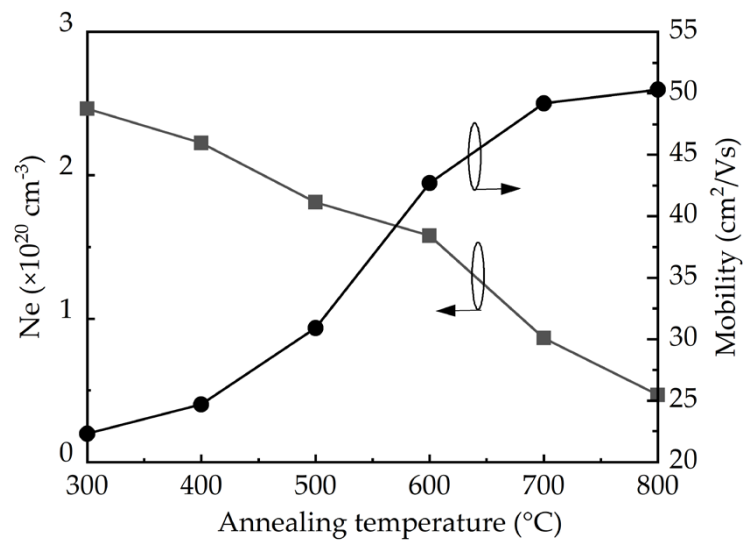

(b)

Figure 4. (a) Resistivity, (b) carrier concentration, Ne, and mobility determined by Hall-effect measurements as a function of annealing temperature.

The optical properties of the AALD Al:ZnO samples with different annealing temperature are investigated. Figure 5 a shows the transmittance and reflectance spectra over the $350-950 \mathrm{~nm}$ wavelengths for the bare glass and the AALD Al: $\mathrm{ZnO}$ films annealed at different temperatures. Compared to the glass substrate, all the Al:ZnO films exhibit a lower transmittance, due to the significantly higher reflectance. To exclude the impact of the reflectance, the absorption coefficient $(\alpha)$ is used for assess the optical property of the films and calculated by:

$$
\alpha=-\frac{1}{d} \ln \left[\frac{T}{(1-R)^{2}}\right],
$$

where $d$ is the thickness of the films, $T$ is the transmittance, and $R$ is the reflectance. The result is shown in Figure $5 \mathrm{~b}$. The high absorption coefficients at the short-wavelengths $(<400 \mathrm{~nm})$ are due to the band-to-band absorption where the photon energy is close to the material band gap [45]. The increased absorption coefficient at increasing annealing temperature is related to the better crystalline structure with less oxygen vacancies. All the films exhibit similarly low absorption coefficients at the longer wavelengths. Figure $5 c$ shows the band gap, calculated using Tauc's plot method [46], of the AALD $\mathrm{Al}: \mathrm{ZnO}$ films with different annealing temperature. The band gap slightly decreases from 300 to $500^{\circ} \mathrm{C}$. Further increasing the annealing temperature leads to a sharp increase in band gap. For Al:ZnO films, band gap variation is usually associated with the carrier concentration. When the carrier concentration exceeds the Mott critical density $\left(\sim 10^{19} \mathrm{~cm}^{-3}\right.$ for ZnO-based films), the Burstein-Moss band filling effect occurs to increase the band gap and the increment is proportional to the $\mathrm{N}_{\mathrm{e}}^{2 / 3}[47,48]$. This linear 
relationship is observed in the annealing temperatures of $300-500{ }^{\circ} \mathrm{C}$ in the present work. We therefore suspected that the reduction of the band gap can be attributed to the decreased carrier concentration and the less pronounced Burstein-Moss effect. The increased tendency of the band gap after $500{ }^{\circ} \mathrm{C}$ implies different mechanism. In addition to acting as the shallow donors, in some cases oxygen vacancies can introduce mid-gap states. The significant increase in band gap at $600-800{ }^{\circ} \mathrm{C}$ is possibly due to the reduction of the mid-gap states caused by the microstructure restoration or the removal of the mid-gap state oxygen vacancies. Similar results associated with the band gap enlargement due to the mid-gap state elimination in metal oxides are reported elsewhere [49]. Figure 5d shows the refractive indices of the samples annealed at different temperature. The refractive index increases with the annealing temperature increasing from $300-700{ }^{\circ} \mathrm{C}$, due to the improved crystalline structure, as evidenced by XRD, and film density. The $800^{\circ} \mathrm{C}$-annealed sample has a reduced refractive index, which is commonly linked to the decreased density. As observed from SEM image, the enhanced grain boundaries and voids at $800{ }^{\circ} \mathrm{C}$ may account for the reduced density of the film.

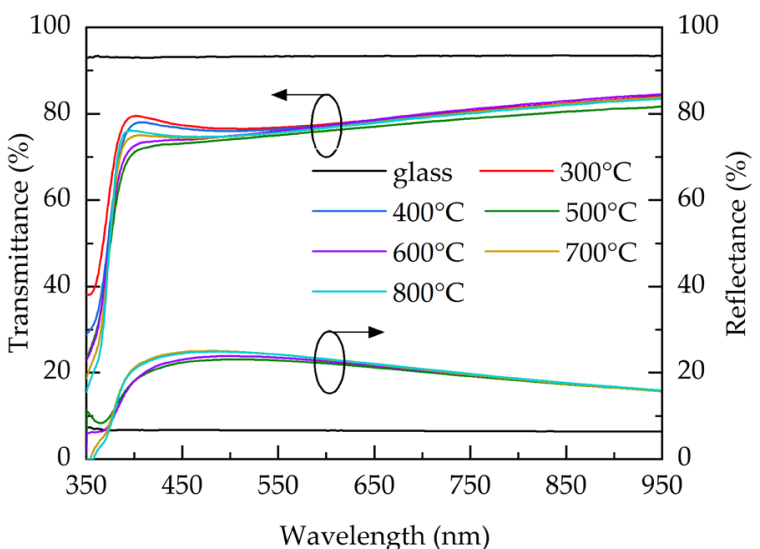

(a)

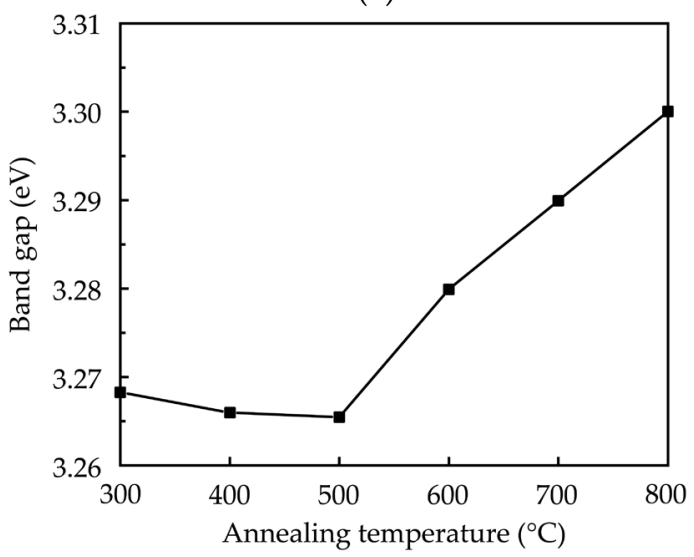

(c)

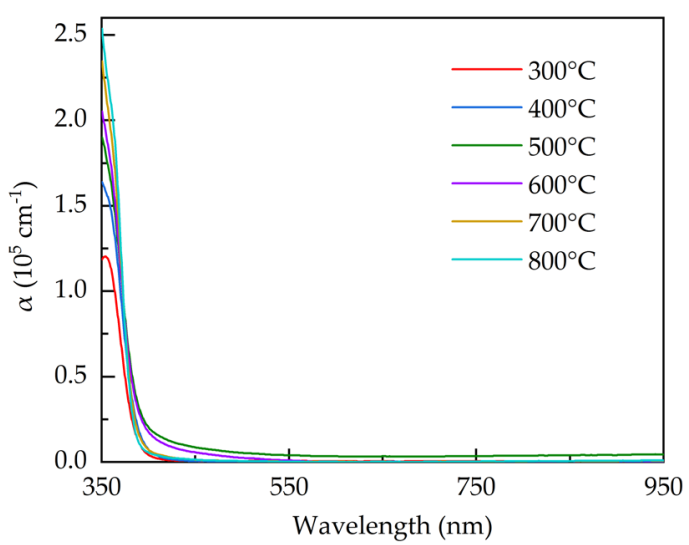

(b)

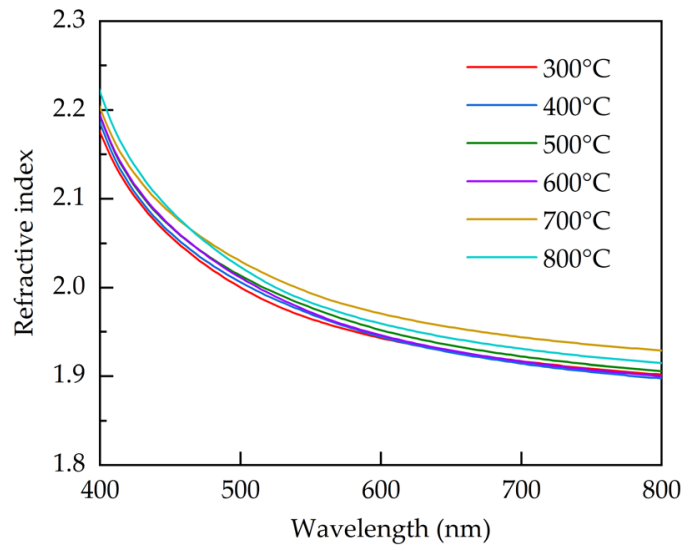

(d)

Figure 5. (a) Transmittance and reflectance spectra, (b) absorption coefficient spectra, (c) band gap, and (d) refractive index for the AALD Al:ZnO films with different annealing temperature.

\section{Experimental}

Glass substrates with a size of $2 \mathrm{~cm} \times 2 \mathrm{~cm}$ were ultrasonically cleaned in alcohol, acetone and deionized water for $15 \mathrm{~min}$ each, and then dried in nitrogen and placed in an oven at $80{ }^{\circ} \mathrm{C}$ for at least $30 \mathrm{~min}$. The $\mathrm{Al}: \mathrm{ZnO}$ films were deposited via a homemade AALD system having injector heads connected to trimethylaluminum (TMA), diethylzinc (DEZ) and oxidant $\left(\mathrm{H}_{2} \mathrm{O}\right)$. The metal precursors (purity: 99.9999\%) were purchased from Aimou Yuan Scientific (Nanjing, China), and were co-introduced into the deposition region. The schematic diagram of the AALD system is shown 
in Figure 6a. The injection heads were arranged in the order of $\mathrm{H}_{2} \mathrm{O}$, (DEZ+TMA), and $\mathrm{H}_{2} \mathrm{O}$, each separated by nitrogen gas curtains. The temperatures of the TMA, DEZ, and $\mathrm{H}_{2} \mathrm{O}$ bubblers were controlled to be 40,40 and $30^{\circ} \mathrm{C}$, respectively, using the heating water baths. Nitrogen gas was used as carrier gas, dilution gas and gas curtain. During AALD deposition, the samples were placed on a substrate holder in the air atmosphere. The substrate holder moved horizontally back and forth at a speed of $150 \mathrm{~mm} / \mathrm{s}$, and stopped for about $0.5 \mathrm{~s}$ when it reached both ends. The distance between the injection head and the substrate was $0.3 \mathrm{~mm}$. Table 1 summarizes the detailed deposition parameters for the Al:ZnO films.

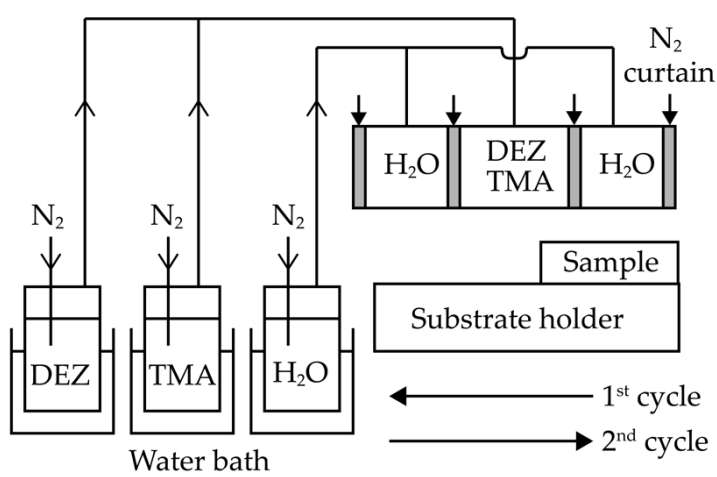

(a)

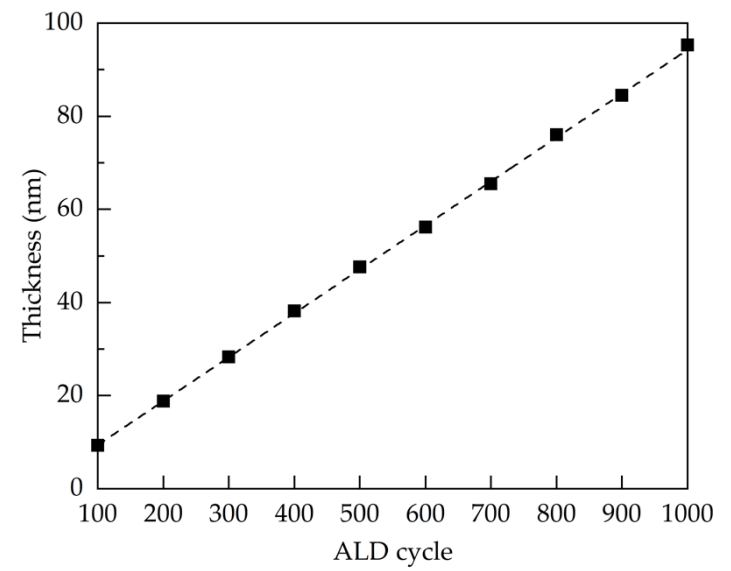

(b)

Figure 6. (a) Schematic diagram of the AALD system, and (b) thickness of the Al:ZnO films as a function of the ALD cycle.

Table 1. Deposition parameters for AALD Al:ZnO films.

\begin{tabular}{cc}
\hline Parameter & Value \\
\hline Annealing temperature $\left({ }^{\circ} \mathrm{C}\right)$ & $300-800$ \\
Substrate temperature $\left({ }^{\circ} \mathrm{C}\right)$ & 110 \\
Substrate holder moving speed $(\mathrm{cm} / \mathrm{s})$ & 15 \\
Distance between injector and substrate $(\mathrm{mm})$ & 0.3 \\
$\mathrm{H}_{2} \mathrm{O}$ carrier gas flow rate $(\mathrm{sccm})$ & 400 \\
$\mathrm{H}_{2} \mathrm{O}$ dilution gas flow rate $(\mathrm{sccm})$ & 800 \\
Precursor carrier gas flow rate $(\mathrm{sccm})$ & 200 \\
Precursor dilution gas flow rate $(\mathrm{sccm})$ & 1100 \\
TMA and DEZ bubbler temperature $\left({ }^{\circ} \mathrm{C}\right)$ & 40 \\
\hline
\end{tabular}

When the substrate moved beneath the injector, the substrate firstly received the exposure of $\mathrm{H}_{2} \mathrm{O}$ to generate $-\mathrm{OH}$ species on the substrate surface. The substrate then moved to the metal precursors co-injection zone. The surface $\mathrm{OH}$ ligands reacted with the metal precursors to create $\mathrm{O}-\mathrm{Al}$ or $\mathrm{O}-\mathrm{Zn}$ bonds, and the surface species changed to $-\mathrm{CH}_{3}$ or $-\mathrm{C}_{2} \mathrm{H}_{5}$, as given by:

$$
\mathrm{S}-\mathrm{OH}+\mathrm{Al}-\left(\mathrm{CH}_{3}\right)_{3} \text { or } \mathrm{Zn}\left(\mathrm{C}_{2} \mathrm{H}_{5}\right)_{2} \rightarrow \mathrm{S}-\mathrm{O}-\mathrm{Al}-\left(\mathrm{CH}_{3}\right)_{2} \text { or S-O-Zn( }\left(\mathrm{C}_{2} \mathrm{H}_{5}\right)+\mathrm{CH}_{4} \text { or } \mathrm{C}_{2} \mathrm{H}_{6} \text {, }
$$

where $\mathrm{S}$ denotes the substrate surface. Noted that there were exhaust holes between the $\mathrm{H}_{2} \mathrm{O}$ and the metal precursors injectors to remove the excess precursor molecules or by-products. When the substrate arrived the next $\mathrm{H}_{2} \mathrm{O}$ injection zone, the surface ligands changed to the initial state (-OH species) again as given by:

$$
\text { S-O-Al- }\left(\mathrm{CH}_{3}\right)_{2} \text { or S-O-Zn }\left(\mathrm{C}_{2} \mathrm{H}_{5}\right)+\mathrm{H}_{2} \mathrm{O} \rightarrow \mathrm{S}-\mathrm{O}-\mathrm{Al}-\mathrm{OH} \text { or S-O-Zn-OH }+\mathrm{CH}_{4} \text { or } \mathrm{C}_{2} \mathrm{H}_{6}
$$

After the surface reactions (1) and (2), one ALD cycle was completed and repeated by moving the substrate back and forth beneath the injection head until the required film thickness was obtained. 
Figure $6 \mathrm{~b}$ shows the film thickness as a function of the ALD cycle. The error of the film thickness was within $\pm 1.5 \%$. The linear relationship indicated the self-limiting nature of the ALD process. The growth per cycle was about $0.94 \mathrm{~nm} /$ cycle. To study the annealing effects on the properties of the films, the $\mathrm{Al}: \mathrm{ZnO}$ films were prepared at a thickness of $60 \mathrm{~nm}$, corresponding to the ALD cycle number of 635 , and then received a post-deposition annealing process at different temperatures ranging from 300 to $800{ }^{\circ} \mathrm{C}$ in a diffusion furnace (FRD-002, Friend, Qingdao, China) in ambient air. The transmittance and reflectance spectra of the films were obtained by using a UV-visible spectrometer (MFS-630, Hong-Ming Technology, New Taipei City, Taiwan). The refractive indices and thickness of the films were determined by an ellipsometer (M2000, J. A. Woollam, Lincoln, NE, USA). The X-ray diffraction (XRD, Rigaku TTRAXIII, Ibaraki, Japan) measurements were carried out at an incident angle of $0.5^{\circ}$ to investigate the crystal structure of the films. The X-ray photoelectron spectroscopy (XPS, ESCALAB 250Xi, Thermo Fisher, Waltham, MA, USA) with Al-K $\alpha$ anode was employed to obtain the chemical states and elemental ratio of the films. The Hall-effect measurements (HMS5000, Side Semiconductor Technology, Shanghai, China) were conducted to determine the resistivity, carrier concentration, and mobility of the films. The surface morphologies of the samples were observed using a scanning electron microscopy (SEM, sigma 500, Zeiss, Oberkochen, Germany).

\section{Conclusions}

$\mathrm{Al}$-doped $\mathrm{ZnO}$ films are prepared using high-growth rate AALD and receives a post-annealing process with different annealing temperature in air. The XPS result evidences the reduction of the oxygen vacancies, suggesting that the oxygen from the annealing ambient can be incorporated in the films to fill the vacancies. The XRD result also confirms the restoration of the crystalline structure. The annealing at $600{ }^{\circ} \mathrm{C}$ has the lowest resistivity of $9 \times 10^{-4} \Omega$-cm due to the balance between the increased mobility and reduced carrier concentration at increasing annealing temperature. The band gap variation at $300-500{ }^{\circ} \mathrm{C}$ matches the Burstein-Moss effect, suggesting that the low annealing temperature mainly reduce the oxygen vacancies acting as donors. While the higher annealing temperature of above $600^{\circ} \mathrm{C}$ could further reduce the mid-gap states. The AALD Al:ZnO thin films with high transparency and low resistivity provide a promising alternative option to replace the ITO films in solar cell applications.

Author Contributions: Conceptualization, C.-H.H. and S.-Y.L.; methodology, X.-P.G.; formal analysis, C.-H.H., X.-P.G., W.-Y.W., M.-J.Z., X.-Y.Z. and P.-H.H.; data curation, X.-P.G.; writing-original draft preparation, C.-H.H.; writing-review and editing, C.-H.H.; supervision, S.-Y.L.; funding acquisition, C.-H.H. and S.-Y.L. All authors have read and agreed to the published version of the manuscript.

Funding: This work is supported by the scientific research projects of Xiamen University of Technology (nos. 0105-50419030, 30319003, and YKJ19001R). This work is also sponsored by the science and technology project of Xiamen (no. 3502Z20183054) and the Science and Technology Program of the Educational Office of Fujian Province (no. JT180432).

Conflicts of Interest: The authors declare no conflict of interest.

\section{References}

1. Pérez-Tomás, A.; Mingorance, A.; Tanenbaum, D.M.; Lira-Cantu, M. Metal oxides in Photovoltaics: All-oxide, Ferroic, and Perovskite solar cells. In The Future of Semiconductor Oxides in Next-Generation Solar Cells; Elsevier: Amsterdam, The Netherlands, 2018; pp. 267-356. ISBN 978-0-12-811165-9.

2. Coelho, L.; Viegas, D.; Santos, J.L.; De Almeida, J.M.M.M. Characterization of zinc oxide coated optical fiber long period gratings with improved refractive index sensing properties. Sens. Actuators B Chem. 2016, 223, 45-51. [CrossRef]

3. Khan, M.M.; Adil, S.F.; Al-Mayouf, A. Metal oxides as photocatalysts. J. Saudi Chem. Soc. 2015, $19,462-464$. [CrossRef]

4. Dey, A. Semiconductor metal oxide gas sensors: A review. Mater. Sci. Eng. B 2018, 229, 206-217. [CrossRef]

5. Han, H.S.; Park, W.; Sivanantham, A.; Hwang, S.W.; Surendran, S.; Sim, U.; Cho, I.S. Facile fabrication of nanotubular heterostructure for enhanced photoelectrochemical performance. Ceram. Int. 2020. [CrossRef] 
6. Han, H.S.; Park, W.; Hwang, S.W.; Kim, H.; Sim, Y.; Surendran, S.; Sim, U.; Cho, I.S. (0 2 0)-Textured tungsten trioxide nanostructure with enhanced photoelectrochemical activity. J. Catal. 2020, 389, 328-336. [CrossRef]

7. Surendran, S.; Shanmugapriya, S.; Ramasamy, H.; Janani, G.; Kalpana, D.; Lee, Y.S.; Sim, U.; Selvan, R.K. Hydrothermal deposition of CoS nanostructures and its multifunctional applications in supercapattery and water electrolyzer. Appl. Surf. Sci. 2019, 494, 916-928. [CrossRef]

8. Dong, L.; Zhu, G.S.; Xu, H.; Jiang, X.; Zhang, X.; Zhao, Y.; Yan, D.; Yuan, L.; Yu, A. Fabrication of Nanopillar crystalline ITO thin films with high transmittance and IR reflectance by RF magnetron sputtering. Materials 2019, 12, 958. [CrossRef] [PubMed]

9. Wang, X.; Suwardi, A.; Zheng, Y.; Zhou, H.; Chien, S.W.; Xu, J. enhanced thermoelectric performance of Nanocrystalline indium tin oxide pellets by modulating the density and Nanoporosity via spark plasma sintering. ACS Appl. Nano Mater. 2020, 0c02113. [CrossRef]

10. Hossain, A.; Khoo, K.T.; Cui, X.; Poduval, G.K.; Zhang, T.; Li, X.; Li, W.M.; Hoex, B. Atomic layer deposition enabling higher efficiency solar cells: A review. Nano Mater. Sci. 2020, 2, 204-226. [CrossRef]

11. Le, A.H.T.; Dao, V.A.; Pham, D.P.; Kim, S.; Dutta, S.; Nguyen, C.P.T.; Lee, Y.; Kim, Y.; Yi, J. Damage to passivation contact in silicon heterojunction solar cells by ITO sputtering under various plasma excitation modes. Sol. Energy Mater. Sol. Cells 2019, 192, 36-43. [CrossRef]

12. Demaurex, B.; De Wolf, S.; Descoeudres, A.; Holman, Z.C.; Ballif, C. Damage at hydrogenated amorphous/crystalline silicon interfaces by indium tin oxide overlayer sputtering. Appl. Phys. Lett. 2012, 101, 171604. [CrossRef]

13. Bikowski, A.; Welzel, T.; Ellmer, K. The impact of negative oxygen ion bombardment on electronic and structural properties of magnetron sputtered ZnO:Al films. Appl. Phys. Lett. 2013, 102, 242106. [CrossRef]

14. Ambedkar, A.K.; Singh, M.; Kumar, V.; Kumar, V.; Singh, B.P.; Kumar, A.; Gautam, Y.K. Structural, optical and thermoelectric properties of Al-doped $\mathrm{ZnO}$ thin films prepared by spray pyrolysis. Surf. Interfaces 2020, 19, 100504. [CrossRef]

15. Kim, D.; Yun, I.; Kim, H. Fabrication of rough Al doped ZnO films deposited by low pressure chemical vapor deposition for high efficiency thin film solar cells. Curr. Appl. Phys. 2010, 10, S459-S462. [CrossRef]

16. Kaur, G.; Mitra, A.; Yadav, K. Pulsed laser deposited Al-doped ZnO thin films for optical applications. Prog. Nat. Sci. 2015, 25, 12-21. [CrossRef]

17. Biyikli, N.; Haider, A. Atomic layer deposition: An enabling technology for the growth of functional nanoscale semiconductors. Semicond. Sci. Technol. 2017, 32, 093002. [CrossRef]

18. Gao, Z.; Banerjee, P. Review article: Atomic layer deposition of doped ZnO films. J. Vac. Sci. Technol. A 2019, 37, 050802. [CrossRef]

19. Li, Y.; Yao, R.; Wang, H.; Wu, X.; Wu, J.; Wu, X.; Qin, W. Enhanced performance in Al-doped ZnO based transparent flexible transparent thin-film transistors due to oxygen vacancy in $\mathrm{ZnO}$ film with $\mathrm{Zn}-\mathrm{Al}-\mathrm{O}$ interfaces fabricated by atomic layer deposition. ACS Appl. Mater. Interfaces 2017, 9, 11711-11720. [CrossRef]

20. Kan, Z.; Wang, Z.; Firdaus, Y.; Babics, M.; Alshareef, H.N.; Beaujuge, P.M. Atomic-layer-deposited AZO outperforms ITO in high-efficiency polymer solar cells. J. Mater. Chem. A 2018, 6, 10176-10183. [CrossRef]

21. Banerjee, P.; Lee, W.-J.; Bae, K.-R.; Lee, S.B.; Rubloff, G.W. Structural, electrical, and optical properties of atomic layer deposition Al-doped ZnO films. J. Appl. Phys. 2010, 108, 043504. [CrossRef]

22. Maeng, W.J.; Lee, J.-W.; Lee, J.H.; Chung, K.-B.; Park, J.-S. Studies on optical, structural and electrical properties of atomic layer deposited $\mathrm{Al}$-doped $\mathrm{ZnO}$ thin films with various $\mathrm{Al}$ concentrations and deposition temperatures. J. Phys. D Appl. Phys. 2011, 44, 445305. [CrossRef]

23. Wójcik, A.; Godlewski, M.; Guziewicz, E.; Minikayev, R.; Paszkowicz, W. Controlling of preferential growth mode of $\mathrm{ZnO}$ thin films grown by atomic layer deposition. J. Cryst. Growth 2008, 310, 284-289. [CrossRef]

24. Lee, D.-J.; Kim, H.-M.; Kwon, J.-Y.; Choi, H.; Kim, S.-H.; Kim, K.-B. Structural and electrical properties of atomic layer deposited Al-Doped ZnO films. Adv. Funct. Mater. 2010, 21, 448-455. [CrossRef]

25. Kim, Y.; Lee, W.; Jung, D.-R.; Kim, J.; Nam, S.; Kim, H.; Park, B. Optical and electronic properties of post-annealed ZnO:Al thin films. Appl. Phys. Lett. 2010, 96, 171902. [CrossRef]

26. Lin, S.-S.; Huang, J.-L.; Šajgalik, P. The properties of heavily Al-doped ZnO films before and after annealing in the different atmosphere. Surf. Coat. Technol. 2004, 185, 254-263. [CrossRef]

27. Zhou, Y.; Kelly, P.; Postill, A.; Abu-Zeid, O.; Alnajjar, A. The characteristics of aluminium-doped zinc oxide films prepared by pulsed magnetron sputtering from powder targets. Thin Solid Films 2004, 447, $33-39$. [CrossRef] 
28. Lu, Y.; Wang, S.; Yang, M.; Xu, X.; Li, Q. Comparative study of AZO and ITO thin film sputtered at different temperatures and their application in Cu2ZnSnS4 solar cells. J. Mater. Sci. Mater. Electron. 2018, 29, 17525-17532. [CrossRef]

29. Tseng, C.; Wang, W.; Chang, H.; Chou, C.; Hsu, C.Y. Effects of sputtering pressure and Al buffer layer thickness on properties of AZO films grown by rf magnetron sputtering. Vacuum 2010, 85, 263-267. [CrossRef]

30. Sato, Y.; Yanagisawa, K.; Oka, N.; Nakamura, S.-I.; Shigesato, Y. Sputter deposition of Al-doped ZnO films with various incident angles. J. Vac. Sci. Technol. A 2009, 27, 1166. [CrossRef]

31. Zhou, H.B.; Zhang, H.Y.; Tan, M.L.; Zhang, W.J.; Zhang, W.L. Effects of sputtering pressure on properties of $\mathrm{Al}$ doped $\mathrm{ZnO}$ thin films dynamically deposited by $\mathrm{rf}$ magnetron sputtering. Mater. Res. Innov. 2012, 16, 390-394. [CrossRef]

32. Kim, D.-S.; Park, J.-H.; Shin, B.-K.; Moon, K.-J.; Son, M.; Ham, M.-H.; Lee, W.; Myoung, J.-M. Effect of deposition temperature on the properties of Al-doped $\mathrm{ZnO}$ films prepared by pulsed DC magnetron sputtering for transparent electrodes in thin-film solar cells. Appl. Surf. Sci. 2012, 259, 596-599. [CrossRef]

33. Ku, C.-J.; Duan, Z.; Reyes, P.I.; Lu, Y.; Xu, Y.; Hsueh, C.-L.; Garfunkel, E. Effects of Mg on the electrical characteristics and thermal stability of MgxZn1-xO thin film transistors. Appl. Phys. Lett. 2011, 98, 123511. [CrossRef]

34. Rim, Y.S.; Kim, D.L.; Jeong, W.H.; Kim, H.J. Effect of Zr addition on ZnSnO thin-film transistors using a solution process. Appl. Phys. Lett. 2010, 97, 233502. [CrossRef]

35. Ren, H.; Xiang, G.; Gu, G.; Zhang, X.; Wang, W.; Zhang, P.; Wang, B.Y.; Cao, X. Zinc vacancy-induced room-temperature ferromagnetism in Undoped ZnO thin films. J. Nanomater. 2012, 2012, 1-5. [CrossRef]

36. Han, W.; Kim, J.; Park, H.-H. Control of electrical conductivity of highly stacked zinc oxide nanocrystals by ultraviolet treatment. Sci. Rep. 2019, 9, 1-9. [CrossRef]

37. Manik, P.P.; Mishra, R.K.; Kishore, V.P.; Ray, P.; Nainani, A.; Huang, Y.-C.; Abraham, M.C.; Ganguly, U.; Lodha, S. Fermi-level unpinning and low resistivity in contacts to n-type Ge with a thin $\mathrm{ZnO}$ interfacial layer. Appl. Phys. Lett. 2012, 101, 182105. [CrossRef]

38. Alam, J.; Murkute, P.; Sushama, S.; Ghadi, H.; Mondal, S.; Paul, S.; Das, D.; Pandey, S.K.; Chakrabarti, S. Room-temperature ultraviolet-ozone annealing of $\mathrm{ZnO}$ and $\mathrm{ZnMgO}$ nanorods to attain enhanced optical properties. J. Mater. Sci. Mater. Electron. 2020, 1-14. [CrossRef]

39. Mehmood, F.; Pachter, R.; Murphy, N.R.; Johnson, W.E.; Ramana, C.V. Effect of oxygen vacancies on the electronic and optical properties of tungsten oxide from first principles calculations. J. Appl. Phys. 2016, 120, 233105. [CrossRef]

40. Geng, Y.; Xie, Z.-Y.; Xu, S.-S.; Sun, Q.-Q.; Ding, S.-J.; Lu, H.-L.; Zhang, D.W. Effects of rapid thermal annealing on structural, luminescent, and electrical properties of Al-Doped $\mathrm{ZnO}$ films grown by atomic layer deposition. ECS J. Solid State Sci. Technol. 2012, 1, N45-N48. [CrossRef]

41. Kumar, N.; Chowdhury, A.H.; Bahrami, B.; Khan, M.R.; Qiao, Q.; Kumar, M. Origin of enhanced carrier mobility and electrical conductivity in seed-layer assisted sputtered grown $\mathrm{Al}$ doped $\mathrm{ZnO}$ thin films. Thin Solid Films 2020, 700, 137916. [CrossRef]

42. Mrabet, C.; Mahdhi, N.; Boukhachem, A.; Amlouk, M.; Manoubi, T. Effects of surface oxygen vacancies content on wettability of zinc oxide nanorods doped with lanthanum. J. Alloy. Compd. 2016, 688, 122-132. [CrossRef]

43. Jung, J.; Park, H.J.; Kim, S.-I.; Thaiyan, M. Magnetic, structural and optical behavior of cupric oxide layers for solar cells. J. Alloy. Compd. 2016, 686, 616-627. [CrossRef]

44. Singh, J.; Ranwa, S.; Akhtar, J.; Kumar, M. Growth of residual stress-free ZnO films on SiO2/Si substrate at room temperature for MEMS devices. AIP Adv. 2015, 5, 067140. [CrossRef]

45. Meza, D.; Cruz, A.; Morales-Vilches, A.B.; Korte, L.; Stannowski, B. Aluminum-doped zinc oxide as front electrode for rear emitter silicon Heterojunction solar cells with high efficiency. Appl. Sci. 2019, 9, 862. [CrossRef]

46. Tauc, J. Optical properties and electronic structure of amorphous Ge and Si. Mater. Res. Bull. 1968, 3, 37-46. [CrossRef]

47. Gibbs, Z.M.; LaLonde, A.; Snyder, G.J. Optical band gap and the Burstein-Moss effect in iodine doped PbTe using diffuse reflectance infrared Fourier transform spectroscopy. New J. Phys. 2013, 15, 075020. [CrossRef] 
48. Gahlawat, S.; Singh, J.; Yadav, A.K.; Ingole, P.P. Exploring Burstein-Moss type effects in nickel doped hematite dendrite nanostructures for enhanced photo-electrochemical water splitting. Phys. Chem. Chem. Phys. 2019, 21, 20463-20477. [CrossRef]

49. Mallika, A.N.; Reddy, A.R.; Reddy, K.V. Annealing effects on the structural and optical properties of ZnO nanoparticles with PVA and CA as chelating agents. J. Adv. Ceram. 2015, 4, 123-129. [CrossRef]

Sample Availability: The samples of compounds are not available from the authors.

Publisher's Note: MDPI stays neutral with regard to jurisdictional claims in published maps and institutional affiliations.

(C) 2020 by the authors. Licensee MDPI, Basel, Switzerland. This article is an open access article distributed under the terms and conditions of the Creative Commons Attribution (CC BY) license (http://creativecommons.org/licenses/by/4.0/). 